Article

\title{
Evaluation of the Homogeneity of the Uranium Isotope Composition of NIST SRM 610/611 by MC-ICP-MS, MC-TIMS, and SIMS
}

\author{
Mindy M. Zimmer *, William S. Kinman, Azim H. Kara and Robert E. Steiner \\ Los Alamos National Laboratory, P.O. Box 1663, Los Alamos, NM 87545, USA; \\ E-Mails: wkinman@lanl.gov (W.S.K.); azim@lanl.gov (A.H.K.); steiner@lanl.gov (R.E.S.) \\ * Author to whom correspondence should be addressed; E-Mail: mzimmer@lanl.gov; \\ Tel.: +1-505-667-8288; Fax: +1-505-665-4955.
}

Received: 8 March 2014; in revised form: 31 May 2014 / Accepted: 4 June 2014 /

Published: 10 June 2014

\begin{abstract}
As analytical and microanalytical applications employing uranium isotope ratios increase, so does the need for reliable reference materials, particularly in the fields of geochemistry, geochronology, and nuclear forensics. We present working values for uranium isotopic data of NIST 610/611 glass, collected by multicollector inductively-coupled plasma mass spectrometry (MC-ICP-MS), multicollector thermal ionization mass spectrometry (MC-TIMS), and secondary ion mass spectrometry (SIMS). The presence of depleted U, and, in this case, measureable ${ }^{236} \mathrm{U}$, makes NIST $610 / 611$ an ideal candidate for a uranium isotopic reference material for nuclear materials. We analyzed multiple chips of three different NIST 611 wafers and found no heterogeneity in ${ }^{234} \mathrm{U} /{ }^{238} \mathrm{U},{ }^{235} \mathrm{U} /{ }^{238} \mathrm{U}$, and ${ }^{236} \mathrm{U} /{ }^{238} \mathrm{U}$ within or between the wafers, within analytical uncertainty. We determined working values and uncertainties (using a coverage factor of two) using data from this study and the literature for the following $\mathrm{U}$ isotope ratios: ${ }^{234} \mathrm{U} /{ }^{238} \mathrm{U}=9.45 \times 10^{-6} \pm 5.0 \times 10^{-8}$; ${ }^{235} \mathrm{U} /{ }^{238} \mathrm{U}=2.38555 \times 10^{-3} \pm 4.7 \times 10^{-7}$; and ${ }^{236} \mathrm{U} /{ }^{238} \mathrm{U}=4.314 \times 10^{-5} \pm 4.0 \times 10^{-8}$. SIMS data show ${ }^{235} \mathrm{U} /{ }^{238} \mathrm{U}$ is reproducible to within $1 \%$ (within analytical uncertainty) in a single wafer, at a scale of $25 \mu \mathrm{m}$. Multiple studies have demonstrated homogeneity between wafers of NIST 610 and NIST 611, thus the data reported here can be considered representative of NIST 610 as well.
\end{abstract}

Keywords: NIST SRM 610; NIST SRM 611; uranium isotopes; mass spectrometry; microanalysis; MC-ICP-MS; MC-TIMS; SIMS 


\section{Introduction}

Uranium isotope ratios are useful signatures in $U$ series geochemistry [1-3], radiochronometry/geochronology [4,5], nuclear forensics and nuclear nonproliferation studies [6,7]. Microanalytical techniques including secondary ion mass spectrometry (SIMS) and laser ablation inductively-coupled mass spectrometry (LA-ICP-MS) have made high precision, spatially resolved analysis of $U$ isotope ratios possible, which has yielded new insights into complex materials [8-11]. For example, the isotopes of $U$ in glassy fallout debris from a historical nuclear test have been shown to be heterogeneously distributed [12,13]. This spatially-resolved data may provide valuable information missed via bulk analysis methods. Expanded use of microbeam isotope ratio measurement techniques has highlighted a growing need for homogenous and well-characterized uranium isotope microbeam standards [10,14]. The NIST SRM 600 series of glass standards were prepared by the National Bureau of Standards (now National Institute of Standards and Technology, NIST) for use as calibration standards for in-situ trace element analysis. Although these glass standards are not certified with respect to $U$ isotope composition, they can be useful to assess precision and accuracy of U-series laser ablation measurements [10,14]. Several natural glass reference materials have well characterized uranium isotope compositions [15,16], but natural glasses do not contain measurable ${ }^{236} \mathrm{U}$ and thus may not be ideally suited for the high precision and accuracy required for microanalytical assessment of nuclear materials. The NIST SRM 600 series glasses, however, were made using a depleted U source containing measurable ${ }^{236}$ U. NIST SRM $610 / 611$ is a good candidate for a microbeam U isotopic standard, as previous work has indicated that $U$ is homogenously distributed [17-20]. Of the NIST SRM 600 series glasses, NIST 610/611 has the highest concentration of U (nominally $500 \mu \mathrm{g} / \mathrm{g} \mathrm{U}$ ), which is particularly important for the very low abundance isotopes of ${ }^{234} \mathrm{U}$ and ${ }^{236} \mathrm{U}$. Published data on the U isotopic composition of NIST 610/611 exist [17-20], but results vary by technique $[14,17,18]$, and no effort has been specifically aimed at constraining the $U$ isotopic homogeneity [14,17,21].

Here we determine working values for the U isotope composition of NIST 610/611 and investigate the suitability of the reference glass as a microbeam $U$ isotopic reference material. The homogeneity of NIST SRM 610/611 U isotope composition was examined by dissolution and bulk analysis of multiple fragments of glass from three different lots, as well as ion microprobe measurements. We report new working values for the following $U$ isotope ratios for NIST SRM 610/611: ${ }^{234} U /{ }^{238} U,{ }^{235} U /{ }^{238} U$, and ${ }^{236} \mathrm{U} /{ }^{238} \mathrm{U}$.

\section{Samples}

The NIST 600 series trace element glass standards were prepared by doping a base glass of the following composition: $72 \% \mathrm{~m} / \mathrm{m} \mathrm{SiO}_{2}, 12 \% \mathrm{CaO}, 14 \% \mathrm{Na}_{2} \mathrm{O}$, and $2 \% \mathrm{Al}_{2} \mathrm{O}_{3}$ with sixty-one trace elements in varying concentrations, nominally $500 \mu \mathrm{g} / \mathrm{g}$ (NIST 610 and 611), $50 \mu \mathrm{g} / \mathrm{g}$ (NIST 612 and 613), $1 \mu \mathrm{g} / \mathrm{g}$ (NIST 614 and 615), and $0.02 \mu \mathrm{g} / \mathrm{g}$ (NIST 616 and 617) [22,23]. Odd and even numbered glasses from the same series differ only in wafer size: $12 \times 3 \mathrm{~mm}$ (even numbers) and $12 \times 1 \mathrm{~mm}$ (odd numbers). Most elements are present in lower abundances than the nominal concentrations due to dilution by addition of the trace element mixture or loss during manufacturing [23-25]. Depletions in siderophile and chalcophile elements (likely lost to crucibles and/or the furnace), depletions in 
volatiles (in particular the alkali elements and boron), formation of $3 \mathrm{D}$ compositional cords during the caning process, and loss of elements from the glass surface have been observed [18,19,23,24].

Despite documented heterogeneities in the NIST 600 series glass standards, studies have demonstrated that the concentration of $U$ is homogeneously distributed between wafers and within single wafers of NIST SRM 610/611 [17,18]. Barnes et al. [17] randomly sampled glasses along the entire length of the $100 \mathrm{~kg}$ glass canes during production and found that $\mathrm{U}$ was homogeneous, including between NIST 610 and 611 wafers. Previous bulk analysis of small chips (150 mg) of NIST 610 showed no variation in $U$ concentration, within a reproducibility of $\leq 1 \%$ [20]. Microbeam measurements indicate that $\mathrm{U}$ concentration is homogeneously distributed between wafers at scales of $10 \mu \mathrm{m}$ to $1 \mathrm{~cm}$, within uncertainties of $0.2 \%$ to $1 \%$ [19,20]. In this study, three wafers of NIST 611 from three different lots were broken into chips. Two 40-60 mg chips of each wafer were dissolved for analysis. Uranium isotope ratios were measured on purified $U$ fractions from each sample using multicollector inductively coupled plasma mass spectrometry (MC-ICP-MS), and U isotope ratio measurements were made on a smaller subset of samples using multicollector thermal ionization mass spectrometry (MC-TIMS). The isotopic homogeneity of NIST 611 glass on a scale of tens of microns was evaluated by measuring ${ }^{235} \mathrm{U} /{ }^{238} \mathrm{U}$ ratios along a transect of $25 \mu \mathrm{m}$ points in a single piece of the SRM by secondary ion mass spectrometry (SIMS).

\section{Methods}

\subsection{Dissolution and Uranium Purification}

Chips of SRM 611 (40-60 mg) were dissolved in PFA vials in four mL of $16 \mathrm{M} \mathrm{HNO}_{3}$ and four mL 28.9 M HF. The vials were capped and placed on a hotplate to digest at $110^{\circ} \mathrm{C}$ for $24 \mathrm{~h}$. Samples were uncapped and evaporated to dryness at $120{ }^{\circ} \mathrm{C}$. In cases where fragments of undigested material remained, the initial digestion step was repeated. Sample residue remaining following evaporation was dissolved in eight $\mathrm{mL} 16 \mathrm{M} \mathrm{HNO}_{3}$. Aliquots of 20-30 $\mu \mathrm{g} \mathrm{U}$ were taken by mass, evaporated to dryness, and re-dissolved in five $\mathrm{mL}$ of $9 \mathrm{M} \mathrm{HCl}$ for $\mathrm{U}$ purification. Procedural blanks were subjected to the same dissolution and $U$ purification processes. Purified $U$ fractions were prepared for analysis using an anion exchange resin (BioRad AG $1 \times 4,100-200,0.8 \mathrm{~mL}$ column volume). Eluted $U$ fractions were evaporated to dryness at $110{ }^{\circ} \mathrm{C}$ then converted to a nitrate form by dissolving each residue in $1 \mathrm{~mL}$ $16 \mathrm{M} \mathrm{HNO}_{3}$ and evaporating to dryness at $110^{\circ} \mathrm{C}$. Muticollector ICP-MS sample fractions were re-suspended in $0.32 \mathrm{M} \mathrm{HNO}_{3}$ for analysis. All reagents were prepared using ultra-high purity acids (Fisher Optima ${ }^{\mathrm{TM}}$ grade) and triple distilled $\mathrm{H}_{2} \mathrm{O}(18.2 \mathrm{M} \Omega \mathrm{cm})$. Sample preparation and chemistry was carried out in a Class 100 exhausted laminar flow work station within a class 10,000 clean chemistry laboratory at Los Alamos National Laboratory (LANL).

\subsection{Multicollector Inductively Coupled Plasma Mass Spectrometry (MC-ICP-MS)}

Uranium isotope ratio measurements were made using a Thermo Neptune MC-ICP-MS at LANL. Measurements were in low mass resolution mode $(\mathrm{m} / \Delta \mathrm{m}=400)$ using a high stability dual quartz spray chamber, a PFA-ST nebulizer (Elemental Scientific), and a two jump routine with the collector configuration shown in Table 1. Replicate $U$ isotope ratio measurements were made on purified $U$ 
aliquots from each chip of dissolved glass on three separate days. The following general instrument operating parameters were used: an RF power of $1230 \mathrm{~W}$, a cool gas flow rate of $16 \mathrm{~L} / \mathrm{min}$, an auxiliary gas flow of $0.94 \mathrm{~L} / \mathrm{min}$, and a sample gas flow rate of $0.9 \mathrm{~L} / \mathrm{min}$. Instrument operating conditions were optimized daily, and baseline measurements and Faraday gain calibrations were performed at the beginning of each analytical session. Instrumental $U$ blanks were run between each sample and reference material and were subtracted online during analysis. A two-stage rinse protocol utilizing continuous rinse stations was employed between each sample, standard and blank, where the first rinse consisted of $90-120 \mathrm{~s}$ in $0.16 \mathrm{M} \mathrm{HNO}_{3}-0.01 \mathrm{M} \mathrm{HF}$ followed by a $90-120 \mathrm{~s}$ rinse in $0.32 \mathrm{M}$ $\mathrm{HNO}_{3}$. A sample-standard bracketing routine was followed during each analysis session, where every two samples were bracketed by two $U$ isotopic reference materials diluted to a $U$ concentration similar to the samples. A ${ }^{236} \mathrm{U}$-free reference material, NIST SRM U960 (natural U metal that is the same material as NBL CRM-112A [26]), was run as one reference material with each analysis set to assess and correct ${ }^{235} \mathrm{UH}^{+}$contributions at ${ }^{236} \mathrm{U}$. Average observed hydride contribution, measured as $236.05 /{ }^{238} \mathrm{U}$ in U960, was $1.35 \times 10^{-6}$. The reference materials NBL CRM-U010 [27], and NBL CRM-U-005-A [28] were used for mass bias correction. Mass bias corrections were calculated and applied externally using an exponential mass fractionation law. Each respective isotope ratio measured in a reference material was used to mass bias correct the same ratio measured in a sample, which for minor isotopes makes it possible to correct for relative gain differences between electron multiplier and Faraday detectors not otherwise captured and corrected. Uncertainty associated with blank subtraction and mass bias correction were propagated in quadrature for individual measurments. Uncertainties on individual measurements are dominated by uncertainties on the reference materials used for mass bias correction purposes (e.g., U-005A uncertainty on ${ }^{236} \mathrm{U} /{ }^{238} \mathrm{U}=0.8 \% 1 \sigma$ and $\mathrm{U}-010$ uncertainty on ${ }^{236} \mathrm{U} /{ }^{238} \mathrm{U}=0.2 \% 1 \sigma$ ). Uncertainties for other isotope ratios in these two reference materials are listed on their respective certificates. Lower concentration solutions were selected for analysis to minimize tailing effects from ${ }^{238} \mathrm{U}^{+}$, where ${ }^{238} \mathrm{U}^{+}$signals ranged from 5 to $6 \mathrm{~V}$ on a Faraday detector and ${ }^{235} \mathrm{U}^{+}$signals on a Faraday detector ranged between 10 and $15 \mathrm{mV}$. Tailing from ${ }^{238} \mathrm{U}^{+}$into ${ }^{236} \mathrm{U}^{+}$was examined using standard reference materials and was determined to be negligible at $\mathrm{m} / \mathrm{z}=236$ and absent at $\mathrm{m} / \mathrm{z}=234$. In consideration of the elevated ${ }^{236} \mathrm{U} /{ }^{238} \mathrm{U}$ ratio of NIST SRM $610 / 611\left({ }^{236} \mathrm{U} /{ }^{238} \mathrm{U}\right.$ nominally $\left.=4.3 \times 10^{-6}\right)$ and minimal tailing from ${ }^{238} \mathrm{U}^{+}$, no tailing correction was applied.

\subsection{Multicollector Thermal Ionization Mass Spectrometry (MC-TIMS)}

Uranium isotope ratios were measured in aliquots of five samples by TIMS. Multicollector TIMS measurements were made using an IsotopX Isoprobe-T multicollector TIMS instrument using the collector configuration shown in Table 1. Aliquots of each sample were loaded on a bed of colloidal graphite. Graphite used for U loading was cleaned extensively prior to use to minimize U blank contribution. Large $U$ aliquots (500 ng) of each sample and corresponding reference materials were loaded on triple Re filament assemblies where U isotopes were collected simultaneously on Faraday and Daly detectors (Table 1). Uranium isotopic analyses were run using a three magnet jump method, where minor $U$ isotopes were measured on the axial Daly detector and all other isotopes were measured on Faraday detectors. Baseline measurements and detector gain calibrations were run daily. Ratios of ${ }^{234} \mathrm{U} /{ }^{238} \mathrm{U},{ }^{235} \mathrm{U} /{ }^{238} \mathrm{U}$, and ${ }^{236} \mathrm{U} /{ }^{238} \mathrm{U}$ were used to determine the Faraday/Daly relative gain. 
The average measured $236.05 /{ }^{238} \mathrm{U}$ in U960 was $3.7 \times 10^{-9}$ with an uncertainty overlapping zero, which indicated that tailing effects and ${ }^{235} \mathrm{UH}^{+}$contributions were negligible. No tailing or hydride corrections were made. External mass bias corrections were calculated using an exponential mass fractionation law and the following reference materials: NBL CRM-112A [26], NBL CRM-U-010 [27], and NBL CRM-U-500 [29], and uncertainties on individual measurements due to mass bias correction were propagated in quadrature. Standard reference materials were run at similar concentrations to the samples. Each respective isotope ratio measured in a reference material was used to mass bias correct the same ratio measured in a sample, which for minor isotopes makes it possible to correct for relative gain differences between the Daly and Faraday detectors not otherwise captured and corrected.

Table 1. The axial ion counter used on the IsotopX Isoprobe- $T$ is a Daly electron photomultiplier detector that is linear up to greater than three million cps. The axial ion counter on the Neptune multicollector inductively-coupled plasma mass spectrometry (MC-ICP-MS) consists of a discrete dynode secondary electron multiplier. The L1 Faraday detector on the IsotopX Isoprobe-T thermal ionization mass spectrometry (TIMS) instrument is the axial Faraday detector, moved to the L1 position, which allows for simultaneous use of the axial Faraday and the Daly detector. Cup positions were aligned before MC-ICP-MS and multicollector thermal ionization mass spectrometry (MC-TIMS) analysis sessions using NBL CRM-U-500. Faraday gain calibrations were run prior to each analytical session using a controlled internal voltage.

\begin{tabular}{|c|c|c|c|c|c|c|c|}
\hline \multicolumn{8}{|c|}{ IsotopX Isoprobe-T MC-TIMS Collector Configuration } \\
\hline Magnet Configuration & L1 & Daly & H1 & H2 & H3 & H4 & H5 \\
\hline Jump 1 & & ${ }^{234} \mathrm{U}$ & ${ }^{235} \mathrm{U}$ & ${ }^{236} \mathrm{U}$ & & ${ }^{238} \mathrm{U}$ & \\
\hline Jump 2 & & ${ }^{235} \mathrm{U}$ & ${ }^{236} \mathrm{U}$ & & ${ }^{238} \mathrm{U}$ & & \\
\hline Jump 3 & ${ }^{235} \mathrm{U}$ & ${ }^{236} \mathrm{U}$ & & ${ }^{238} \mathrm{U}$ & & & \\
\hline \multicolumn{8}{|c|}{ Thermo Neptune MC-ICP-MS Collector Configuration } \\
\hline Magnet Configuration & $\mathbf{L 1}$ & SEM & H1 & $\mathbf{H 2}$ & H3 & H4 & \\
\hline Jump 1 & & ${ }^{234} \mathrm{U}$ & ${ }^{235} \mathrm{U}$ & ${ }^{236} \mathrm{U}$ & & ${ }^{238} \mathrm{U}$ & \\
\hline Jump 2 & ${ }^{235} \mathrm{U}$ & ${ }^{236} \mathrm{U}$ & & ${ }^{238} \mathrm{U}$ & & & \\
\hline
\end{tabular}

\subsection{Secondary Ion Mass Spectrometry (SIMS)}

A single wafer of NIST 611 was polished to $1 \mu \mathrm{m}$ with diamond suspension, mounted in indium, and coated with $\sim 30 \mathrm{~nm}$ of gold. In situ ${ }^{235} \mathrm{U} /{ }^{238} \mathrm{U}$ measurements were made using a CAMECA IMS 1280 SIMS at LANL using a focused ${ }^{16} \mathrm{O}^{-}$beam of $20 \mathrm{nA}$ with a net energy of $23 \mathrm{keV}(+13 \mathrm{keV}$ primary accelerating voltage). Secondary ions were detected using a single electron multiplier. The transfer section was tuned to image an $80 \mu \mathrm{m}$ field of view, with a contrast aperture of $400 \mu \mathrm{m}$ and a field aperture of $4000 \mu \mathrm{m}$. Entrance slits were set at $122 \mu \mathrm{m}$. A $50 \mathrm{eV}$ energy window was used, with the inner edge set to $5 \mathrm{eV}$ higher than the peak in the energy distribution. Mass resolving power (MRP) was set to 4000, as this MRP was adequate to resolve a likely ${ }^{207} \mathrm{~Pb}^{28} \mathrm{Si}^{+}$interference on ${ }^{235} \mathrm{U}$. A $40 \mu \mathrm{m}^{2}$ rastered area was pre-sputtered for $120 \mathrm{~s}$, and then reduced to a $25 \mu \mathrm{m}^{2}$ rastered area during analysis. Analyses consisted of 5 blocks of 10 cycles, with counting times of $2 \mathrm{~s}$ for ${ }^{235} \mathrm{U}$ and ${ }^{238} \mathrm{U}$. Prior to each analysis, automatic centering routines were employed for mass calibration, energy, and beam centering 
in the transfer section, for a total analysis time of $25 \mathrm{~min}$. An in-house glass standard doped with NBL CRM-U-500 [29] was used for instrument and detector set up, with final tuning performed on NIST 611 immediately prior to analysis. Data was corrected for dead time and background using manufacturer software.

\section{Results and Discussion}

Results of individual MC-ICP-MS and MC-TIMS measurements of U isotope ratios in 40-60 mg pieces of NIST SRM 611 and individual measurement uncertainties are shown in Figure 1 (see also Supplementary Table S1). Estimates of uncertainty shown for individual measured isotope ratios are standard deviations on internal independent observations propagated in quadrature, with a coverage factor of two, calculated in accordance with ISO 98-1:2009 [30]. Individual measurement uncertainties were dominated by uncertainties on $U$ isotope compositions of reference materials used for mass bias correction. For ${ }^{234} \mathrm{U} /{ }^{238} \mathrm{U}$ and ${ }^{236} \mathrm{U} /{ }^{238} \mathrm{U}$, the weighted mean working values and expanded uncertainties listed in Table 2 were calculated using MC-ICP-MS and MC-TIMS data collected in this study only. For ${ }^{235} \mathrm{U} /{ }^{238} \mathrm{U}$, data and uncertainties reported by Stirling et al. [14] were included in the weighted mean working value. The expanded uncertainties represent a pooled standard deviation, with a coverage factor of two, for the data from Table 2 and Figure 1, including data from Stirling et al. [14] for ${ }^{235} \mathrm{U} /{ }^{238} \mathrm{U}$. The results of Barnes et al. [17] and Duffin et al. [21] were excluded from the weighted mean working values and expanded uncertainties listed in Table 2.

Table 2. Working U isotope ratios values for NIST SRM 610/611.

\begin{tabular}{cccc}
\hline & ${ }^{234} \mathbf{U} /{ }^{238} \mathbf{U}$ & ${ }^{235} \mathbf{U} /{ }^{238} \mathbf{U}$ & ${ }^{236} \mathbf{U} /{ }^{238} \mathbf{U}$ \\
\hline Mean $^{*}$ & $9.45 \times 10^{-6}$ & $2.39555 \times 10^{-3}$ & $4.314 \times 10^{-5}$ \\
Uncertainty $^{* *}$ & $5.0 \times 10^{-8}$ & $4.7 \times 10^{-7}$ & $4.0 \times 10^{-8}$ \\
\hline
\end{tabular}

Notes: ${ }^{*}$ Mean $=$ weighted mean of 35 MC-ICP-MS and MC-TIMS measurements from this study. The ${ }^{235} \mathrm{U} /{ }^{238} \mathrm{U}$ weighted mean includes nine measurements from Stirling et al. [14]. ${ }^{* *}$ Uncertainty $=$ pooled standard deviation of all analytical sessions and literature data, where appropriate, with a coverage factor of two: $S D_{\text {pooled }}=\sqrt{\frac{\left(n_{1}-1\right)_{S D 1}^{2}+\left(n_{2}-1\right)_{S D 2}^{2}+\ldots+\left(n_{k}-1\right)_{S D k}^{2}}{n_{1}+n_{2}+\ldots+n_{k}-k}}$.

\subsection{Matrix Complications When Using NIST SRM 610/611 as a U isotope Microbeam Standard}

Femtosecond laser ablation ICP-MS results reported by Duffin et al. [21] do not overlap results reported in this study nor those reported by Stirling et al. [14] (Figure 1). While the origin of this poor agreement is not entirely clear, it is likely influenced by transient ${ }^{194-198} \mathrm{Pt}^{36-40} \mathrm{Ar}^{+}$polyatomic interferences that affect ${ }^{234} \mathrm{U}^{+},{ }^{235} \mathrm{U}^{+},{ }^{236} \mathrm{U}^{+}$, and ${ }^{238} \mathrm{U}^{+}$(Table 3), with ${ }^{194-198} \mathrm{Pt}^{40} \mathrm{Ar}^{+}$interferences generating the greatest contributions [21]. The NIST 600 series glasses were produced via melting base glass materials in a large Pt crucible within a Pt-Rh lined furnace [17,22]. Eggins and Shelley [18] documented Pt-rich heterogeneities (Cu-Pt domains) within NIST 600 series glasses. If Pt-rich domains are encountered during microbeam sampling, the contributions by the interferences listed in Table 3 become non-trivial. NIST SRM 610/611 contains $453.3 \mu \mathrm{g} / \mathrm{g}$ total $\mathrm{U}$ [31], and using the working values listed in Table 2 , this equates to $0.002 \mu \mathrm{g} / \mathrm{g}{ }^{234} \mathrm{U}, 1.08 \mu \mathrm{g} / \mathrm{g}{ }^{235} \mathrm{U}$, and $0.02 \mu \mathrm{g} / \mathrm{g}{ }^{236} \mathrm{U}$. 
Sylvester and Eggins [24] reported a Pt concentration in NIST SRM 610 of approximately $3 \mu \mathrm{g} / \mathrm{g}$. Uranium-234 is the most affected by Pt-Ar interferences, both because of the greater number of Pt-Ar interferences at mass 234 (Table 3), and because it is the least abundant U isotope in NIST SRM $610 / 611$. Indeed, the ${ }^{234} U /{ }^{238} U$ ratios reported by Duffin et al. [21] exhibit the poorest agreement with data from this study and Stirling et al. [14] (Figure 1). A mass resolving power of $>2000$ is required to mitigate the Pt-Ar interferences listed in Table 3, and the resulting lower transmission makes the measurement of the minor $U$ isotopes more challenging.

Figure 1. Results of individual U isotope measurements of NIST SRM 610/611 from three MC-ICP-MS analysis sessions and one MC-TIMS session are plotted against the weighted mean (dotted line) and expanded uncertainty (Unc.; grey shaded area) of data from this study. Literature data point uncertainties either were not reported or are smaller than the symbols. (A) Individual measurements of ${ }^{234} U /{ }^{238} U$. The data point from Stirling et al. [14] was calculated from their reported activity ratio using ${ }^{234} U T_{1 / 2}=245,250$ years (Cheng et al. [32]) of and ${ }^{238} \mathrm{U} \mathrm{T}_{1 / 2}$ of $4.468 \times 10^{9}$ years (Jaffey et al. [33]). (B) Individual measurements of ${ }^{235} \mathrm{U} /{ }^{238} \mathrm{U}$. Data from Stirling et al. [14] are included in the weighted mean and expanded uncertainty. (C) Individual measurements of ${ }^{236} \mathrm{U}^{238} \mathrm{U}$.

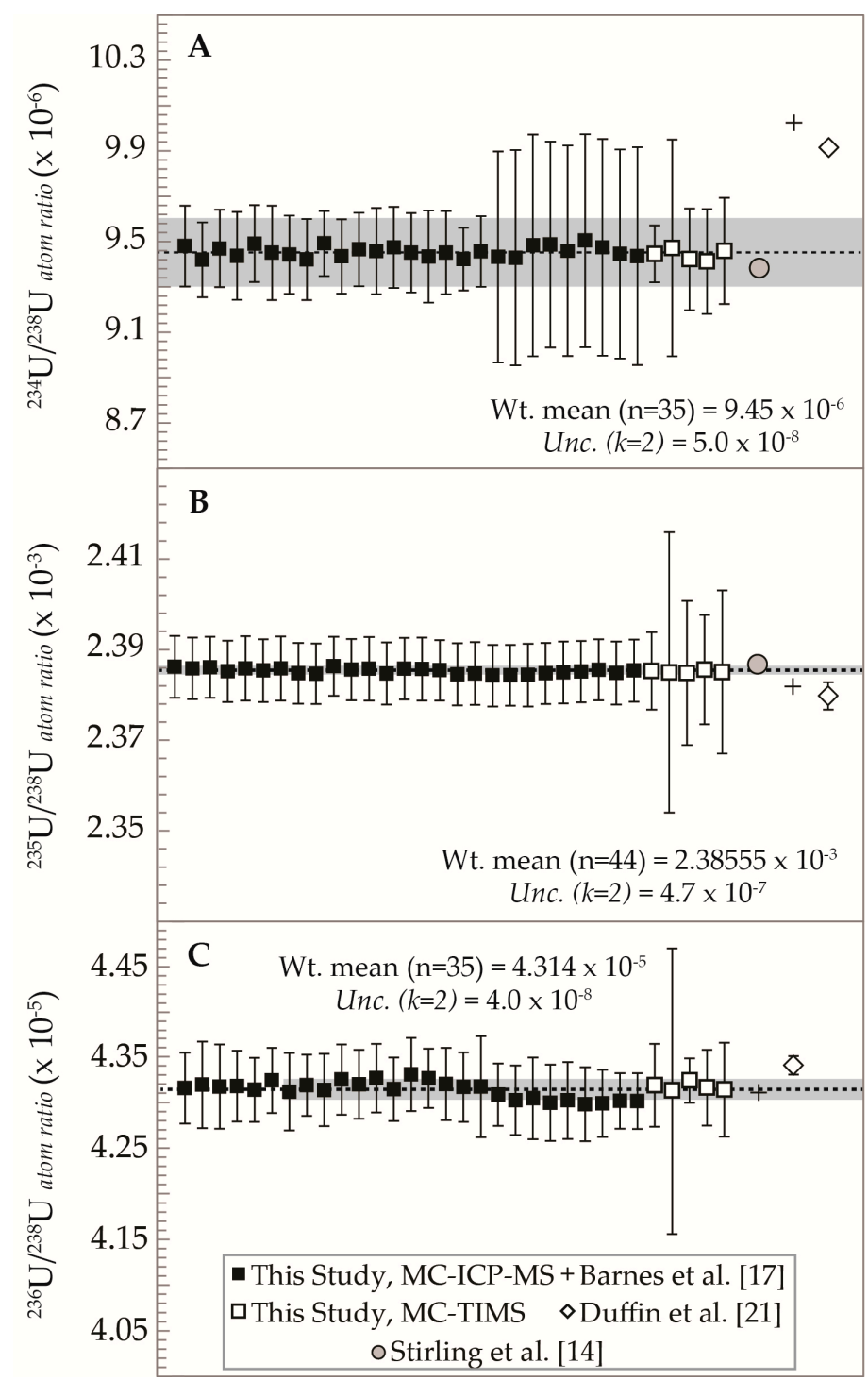


Table 3. Polyatomic interferences affecting uranium isotopes.

\begin{tabular}{|c|c|c|c|c|c|}
\hline${ }^{234} \mathbf{U}$ & ${ }^{194} \mathrm{Pt}^{40} \mathrm{Ar}^{+}$ & ${ }^{196} \mathrm{Pt}^{38} \mathrm{Ar}^{+}$ & ${ }^{198} \mathrm{Pt}^{36} \mathrm{Ar}^{+}$ & ${ }^{204} \mathrm{~Pb}^{30} \mathrm{Si}^{+}$ & ${ }^{206} \mathrm{~Pb}^{28} \mathrm{Si}^{+}$ \\
\hline$\Delta \mathrm{M}$ & 0.12 & 0.11 & 0.11 & 0.09 & 0.09 \\
\hline MRP & 2019 & 2066 & 2218 & 2486 & 2613 \\
\hline${ }^{235} \mathbf{U}$ & ${ }^{195} \mathrm{Pt}^{40} \mathrm{Ar}^{+}$ & ${ }^{206} \mathrm{~Pb}^{29} \mathrm{Si}^{+}$ & ${ }^{207} \mathrm{~Pb}^{28} \mathrm{Si}^{+}$ & & \\
\hline$\Delta \mathrm{M}$ & 0.12 & 0.09 & 0.09 & & \\
\hline MRP & 2013 & 2528 & 2579 & & \\
\hline${ }^{236} \mathbf{U}$ & ${ }^{196} \mathrm{Pt}^{40} \mathrm{Ar}^{+}$ & ${ }^{198} \mathrm{Pt}^{38} \mathrm{Ar}^{+}$ & ${ }^{206} \mathrm{~Pb}^{30} \mathrm{Si}^{+}$ & ${ }^{207} \mathrm{~Pb}^{29} \mathrm{Si}^{+}$ & ${ }^{208} \mathrm{~Pb}^{28} \mathrm{Si}^{+}$ \\
\hline$\Delta \mathrm{M}$ & 0.12 & 0.11 & 0.10 & 0.09 & 0.09 \\
\hline MRP & 1996 & 2053 & 2425 & 2533 & 2566 \\
\hline${ }^{238} \mathbf{U}$ & ${ }^{198} \mathrm{Pt}^{40} \mathrm{Ar}^{+}$ & ${ }^{208} \mathrm{~Pb}^{30} \mathrm{Si}^{+}$ & & & \\
\hline$\Delta \mathrm{M}$ & 0.12 & 0.10 & & & \\
\hline MRP & 1975 & 2371 & & & \\
\hline
\end{tabular}

Lead- $\mathrm{Si}^{+}$polyatomic interferences may also negatively impact the accuracy of $U$ isotope ratios measured using microbeam techniques, requiring an MRP of 2200-2600 (Table 3). Fortunately lead is relatively uniformly distributed in NIST SRM 610/611 [18], such that one can assume the contribution of $\mathrm{Pb}-\mathrm{Si}^{+}$interferences will be more uniform than $\mathrm{Pt}_{-} \mathrm{Ar}^{+}$interferences. In general, $\mathrm{U}$ isotope ratios measured by LA-ICP-MS are acquired in low mass resolution due to loss in ion transmission at higher mass resolutions. Should NIST SRM 610/611 be used as a microbeam U isotopic reference material, careful consideration should be given to the potentially problematic nature of its trace element-rich matrix. NIST 610/611 can be used as a $U$ isotope microbeam reference material with higher confidence where it is possible to measure $U$ isotope ratios at higher mass resolution. For example, the 1280 SIMS does not suffer the same significant loss of ion transmission at high mass resolution that small geometry SIMS and other mass spectrometry techniques experience.

\subsection{Uranium Isotopic Homogeneity of NIST SRM 610/611}

The suitability of NIST SRM 610/611 as a U isotopic microbeam standard is largely dependent on the $\mathrm{U}$ isotopic homogeneity of each wafer. Uranium isotope ratios measured in 6 chips of NIST SRM 611, each representing $10 \%-20 \%$ of the total mass of the different wafers, are plotted against the weighted mean ${ }^{235} \mathrm{U} /{ }^{238} \mathrm{U}$ ratio determined in this study in Figure 2A. These data indicate that NIST SRM 610/611 is isotopically homogeneous on a macroscopic scale (1000s of microns). The $U$ isotopic homogeneity of NIST SRM 610/611 was evaluated on smaller scale by SIMS. Analyses of ${ }^{235} \mathrm{U}^{238} \mathrm{U}$ were performed with $100 \mu \mathrm{m}$ spacing along a single transect from the wafer edge toward the center (total distance $3900 \mu \mathrm{m}$ ) at a MRP sufficient for resolving the polyatomic interferences listed in Table 3 (Supplementary Table S2). The dotted line shown in Figure 2 represents the mean of all SIMS results, and the gray area represents a $2 \sigma$ uncertainty on the mean. Individually measured ${ }^{235} \mathrm{U} /{ }^{238} \mathrm{U}$ are reproducible to within $<1 \%$ at the $1 \sigma$ level at $25 \mu \mathrm{m}$ resolution (probe raster size), with RSDs on the order of $0.8 \%$ to $1.1 \%$ for individual spots (Figure 2). Within the limits of SIMS counting statistics, ${ }^{235} \mathrm{U} /{ }^{238} \mathrm{U}$ shows no compositional heterogeneity in the wafer. Homogeneity of NIST 610/611 can also be assessed from Duffin et al. [21]. The authors did not explicitly examine homogeneity, but they report $>100$ data points, each representing a $30 \mathrm{~s}$ raster, in their Figure 2. We calculated uncertainties 
for ${ }^{234} \mathrm{U} /{ }^{238} \mathrm{U},{ }^{235} \mathrm{U} /{ }^{238} \mathrm{U}$, and ${ }^{236} \mathrm{U} /{ }^{238} \mathrm{U}$ from their average atom \% values for each isotope, which results in $2 \sigma$ uncertainties of $\leq 0.3 \%$ for all ratios, again lending support to the $U$ isotopic homogeneity of NIST $610 / 611$.

Figure 2. (A) The results of an individual ${ }^{235} \mathrm{U} /{ }^{238} \mathrm{U}$ measurement from each of the $40-60 \mathrm{mg}$ pieces from the wafers of NIST SRM 611 (represent 10\%-20\% of the mass of each wafer) are shown against the weighted mean (orange dotted line) and expanded uncertainty (grey shaded area) determined for the SRM in this study. (B) The ${ }^{235} \mathrm{U} /{ }^{238} \mathrm{U}$ ratios measured by SIMS along a $3.9 \mathrm{~mm}$ transect across NIST SRM 611 are plotted against the mean of all SIMS measurements. These results indicate that NIST SRM 610/611 is homogeneous on a scale from $10 \mathrm{~s}$ of $\mu \mathrm{m}$ to $1000 \mathrm{~s}$ of $\mu \mathrm{m}$.

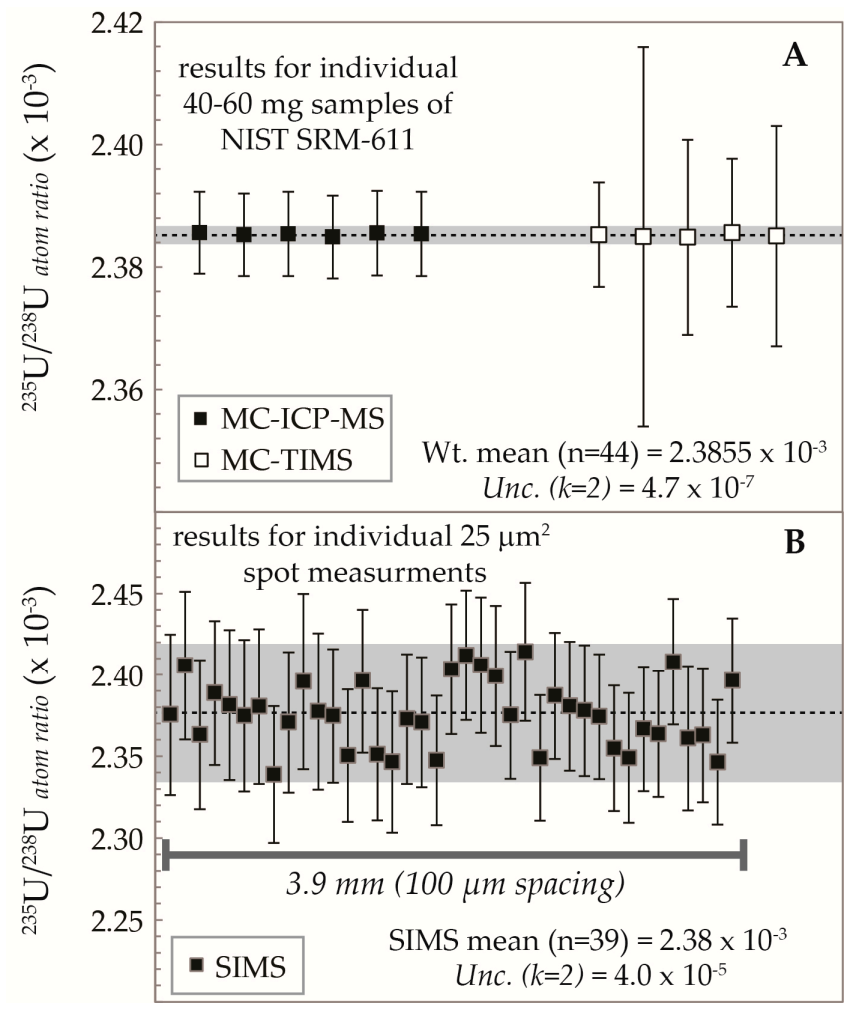

\section{Conclusions}

New high precision uranium isotope ratio measurements of NIST SRM 610/611 glass were collected by MC-ICP-MS and MC-TIMS, and SIMS. Working values for ${ }^{234} \mathrm{U} /{ }^{238} \mathrm{U},{ }^{235} \mathrm{U} /{ }^{238} \mathrm{U}$, and ${ }^{236} \mathrm{U} /{ }^{238} \mathrm{U}$ are presented, with uncertainties calculated in accordance with ISO 98-1:2009. Multiple bulk analyses of 40-60 mg aliquots by MC-ICP-MS and MC-TIMS show no U isotopic heterogeneity, and microanalysis by SIMS shows that ${ }^{235} \mathrm{U} /{ }^{238} \mathrm{U}$ is reproducible to within $1 \%$ (within analytical uncertainty) at a scale of $25 \mu \mathrm{m}$. We conclude that NIST $610 / 611$ is homogeneous at 10 s to $1000 \mathrm{~s}$ of $\mu \mathrm{m}$ and is a suitable reference material for spatially-resolved uranium isotope measurements at the microanalytical scale. However, the trace element-rich matrix of the NIST SRM 600 series glasses requires analysis at higher mass resolving power $(\geq 2000)$ to eliminate potential interferences for techniques that do not involve chemical separation, in particular microbeam analysis. 


\section{Acknowledgments}

This work was funded by the Office of Defense Nuclear Nonproliferation Research and Development within the U.S. Department of Energy's National Nuclear Security Administration. Los Alamos National Laboratory, an affirmative action/equal opportunity employer, is operated by Los Alamos National Security, LLC, for the National Nuclear Security Administration of the U.S. Department of Energy under contract DE-AC52-06NA25396. This manuscript was enhanced by comments from four anonymous reviewers and the editorial office. This publication is LA-UR 14-21457; distribution is unlimited.

\section{Author Contributions}

Mindy M. Zimmer contributed to designing the research, performing the research (sample preparation, MC-ICP-MS analysis and data analysis, SIMS analysis and data analysis), and writing. William S. Kinman contributed to designing the research, performing the research (MC-ICP-MS analysis), data analysis for MC-ICP-MS and MC-TIMS, and writing. Azim H. Kara performed MC-TIMS analysis, data reduction, and contributed to related discussions. Robert E. Steiner contributed to designing the research and data analysis.

\section{Conflicts of Interest}

The authors declare no conflict of interest.

\section{References}

1. Bourdon, B.; Turner, S.; Henderson, G.M.; Lundstrom, C.C. Introduction to U-series geochemistry. In Uranium-Series Geochemistry; Mineralogical Society of Ameri: Chantilly, VA, USA, 2003; Volume 52, pp. 1-21.

2. Gill, J.B.; Williams, R.W. Th-Isotope and U-Series Studies of Subduction-Related Volcanic-Rocks. Geochim. Cosmochim. Acta 1990, 54, 1427-1442.

3. Henderson, G.M.; Anderson, R.F. The U-series toolbox for paleoceanography. Uranium Ser. Geochem. 2003, 52, 493-531.

4. Amelin, Y.; Zaitsev, A.N. Precise geochronology of phoscorites and carbonatites: The critical role of U-series disequilibrium in age interpretations. Geochim. Cosmochim. Acta 2002, 66, 2399-2419.

5. Eggins, S.M.; Grun, R.; McCulloch, M.T.; Pike, A.W.G.; Chappell, J.; Kinsley, L.; Mortimer, G.; Shelley, M.; Murray-Wallace, C.V.; Spotl, C.; et al. In situ U-series dating by laser-ablation multi-collector ICPMS: New prospects for Quaternary geochronology. Quat. Sci. Rev. 2005, 24, 2523-2538.

6. Tamborini, G.; Donohue, D.L.; Rudenauer, F.G.; Betti, M. Evaluation of practical sensitivity and useful ion yield for uranium detection by secondary ion mass spectrometry. J. Anal. At. Spectrom. 2004, 19, 203-208.

7. Mayer, K.; Wallenius, M.; Ray, I. Nuclear forensics-A methodology providing clues on the origin of illicitly trafficked nuclear materials. Analyst 2005, 130, 433-441. 
8. Ranebo, Y.; Hedberg, P.M.L.; Whitehouse, M.J.; Ingeneri, K.; Littmann, S. Improved isotopic SIMS measurements of uranium particles for nuclear safeguard purposes. J. Anal. At. Spectrom. 2009, 24, 277-287.

9. Betti, M.; Tamborini, G.; Koch, L. Use of secondary ion mass spectrometry in nuclear forensic analysis for the characterization of plutonium and highly enriched uranium particles. Anal. Chem. 1999, 71, 2616-2622.

10. Bellucci, J.J.; Simonetti, A.; Wallace, C.; Koeman, E.C.; Burns, P.C. Isotopic fingerprinting of the world's first nuclear device using post-detonation materials. Anal. Chem. 2013, 85, 4195-4198.

11. Varga, Z. Application of laser ablation inductively coupled plasma mass spectrometry for the isotopic analysis of single uranium particles. Anal. Chim. Acta 2008, 625, 1-7.

12. Belloni, F.; Himbert, J.; Marzocchi, O.; Romanello, V. Investigating incorporation and distribution of radionuclides in trinitite. J. Environ. Radioact. 2011, 102, 852-862.

13. Fahey, A.J.; Newbury, D.E. The microstructure of Trinitite, the glassed sand from the first nuclear explosion. Geochim. Cosmochim. Acta 2010, 74, A277-A277.

14. Stirling, C.H.; Lee, D.C.; Christensen, J.N.; Halliday, A.N. High-precision in situ U-238-U-234-Th-230 isotopic analysis using laser ablation multiple-collector ICPMS. Geochim. Cosmochim. Acta 2000, 64, 3737-3750.

15. Denton, J.S.; Murrell, M.T.; Goldstein, S.J.; Nunn, A.J.; Amato, R.S.; Hinrichs, K.A. Evaluation of new geological reference materials for uranium-series measurements: Chinese Geological Standard Glasses (CGSG) and macusanite obsidian. Anal. Chem. 2013, 85, 9975-9981.

16. Matthews, K.A.; Murrell, M.T.; Goldstein, S.J.; Nunn, A.J.; Norman, D.E. Uranium and Thorium Concentration and Isotopic Composition in Five Glass (BHVO-2G, BCR-2G, NKT-1G, T1-G, ATHO-G) and Two Powder (BHVO-2, BCR-2) Reference Materials. Geostand. Geoanal. Res. 2011, 35, 227-234.

17. Barnes, I.L.; Garner, E.L.; Gramlich, J.W.; Moore, L.J.; Murphy, T.J.; Machlan, L.A.; Shields, W.R.; Tatsumot, M.; Knight, R.J. Determination of Lead, Uranium, Thorium, and Thallium in Silicate Glass Standard Materials by Isotope Dilution Mass-Spectrometry. Anal. Chem. 1973, 45, 880-885.

18. Eggins, S.M.; Shelley, J.M.G. Compositional heterogeneity in NIST SRM 610-617 glasses. Geostand. Newsl. 2002, 26, 269-286.

19. Hinton, R.W.; Harte, B.; Witteickschen, G. Ion Probe Measurements of National Institute of Standards and Technology Standard Reference Material SRM-610 Glass, Trace-Elements. Analyst 1995, 120, 1315-1319.

20. Rocholl, A.B.E.; Simon, K.; Jochum, K.P.; Bruhn, F.; Gehann, R.; Kramar, U.; Luecke, W.; Molzahn, M.; Pernicka, E.; Seufert, M.; et al. Chemical characterisation of NIST silicate glass certified reference material SRM 610 by ICP-MS, TIMS, LIMS, SSMS, INAA, AAS and PIXE. Geostand. Newsl. 1997, 21, 101-114.

21. Duffin, A.M.; Hart, G.L.; Hanlen, R.C.; Eiden, G.C. Isotopic analysis of uranium in NIST SRM glass by femtosecond laser ablation MC-ICPMS. J. Radioanal. Nucl. Chem. 2013, 296, 1031-1036.

22. Kane, J.S. A history of the development and certification of NIST glass SRMs 610-617. Geostand. Newsl. 1998, 22, 7-13.

23. Hinton, R.W. NIST SRM 610, 611 and SRM 612, 613 multi-element glasses: Constraints from element abundance ratios measured by microprobe techniques. Geostand. Newsl. 1999, 23, 197-207. 
24. Sylvester, P.J.; Eggins, S.M. Analysis of Re, Au, Pd, Pt and Rh in NIST glass certified reference materials and natural basalt glasses by laser ablation ICP-MS. Geostand. Newsl. 1997, 21, 215-229.

25. Kane, J.S. An assessment of the suitability of NIST glass SRM literature data for the derivation of reference values. Geostand. Newsl. 1998, 22, 15-31.

26. Certificate of Analysis, CRM 112-A; New Brunswick Laboratory: Washington, DC, USA, 2002.

27. Certificate of Analysis, CRM U010; New Brunswick Laboratory: Washington, DC, USA, 1987.

28. Certificate of Analysis, CRM U005-A; New Brunswick Laboratory: Washington, DC, USA, 1987.

29. Certificate of Analysis, CRM U500; New Brunswick Laboratory: Washington, DC, USA, 1987.

30. ISO/IEC 98-1:2009. Uncertainty of Measurement-Part 1: Introduction to the Expression of Uncertainty in Measurement; International Organization for Standardization (ISO): Geneva, Switzerland, 2009.

31. Pearce, N.J.G.; Perkins, W.T.; Westgate, J.A.; Gorton, M.P.; Jackson, S.E.; Neal, C.R.; Chenery, S.P.A compilation of new and published major and trace element data for NIST SRM 610 and NIST SRM 612 glass reference materials. Geostand. Newsl. 1997, 21, 115-144.

32. Cheng, H.; Edwards, R.L.; Hoff, J.; Gallup, C.D.; Richards, D.A.; Asmerom, Y. The half-lives of uranium-234 and thorium-230. Chem. Geol. 2000, 169, 17-33.

33. Jaffey, A.H.; Flynn, K.F.; Glendeni, L.E.; Bentley, W.C.; Essling, A.M. Precision measurement of half-lives and specific activities of U-235 and U-238. Phys. Rev. C 1971, 4, 1889-1906.

(C) 2014 by the authors; licensee MDPI, Basel, Switzerland. This article is an open access article distributed under the terms and conditions of the Creative Commons Attribution license (http://creativecommons.org/licenses/by/3.0/). 